\title{
The importance of lung hyperperfusion patterns in COVID-19-related AVDS
}

\author{
Vincent Jounieaux ${ }^{1}\left[\right.$ D $\cdot$ Yazine Mahjoub ${ }^{2} \cdot$ Isabelle El-Esper ${ }^{3} \cdot$ Daniel Oscar Rodenstein $^{4}$
}

Received: 25 May 2021 / Accepted: 3 June 2021 / Published online: 11 July 2021

(C) The Author(s), under exclusive licence to Springer-Verlag GmbH Germany, part of Springer Nature 2021

\section{Dear Sir,}

We read with great interest the recent letter to the Editor by Lavinia Monaco et al. [1] about the article by Jeeban P. Das et al. [2] that were both published in your European Journal of Nuclear Medicine and Molecular Imaging. In six patients with a laboratory-confirmed diagnosis of COVID19 and a moderate or high pre-test probability of pulmonary embolism (PE), perfusion (Q)-single-photon emission computed tomography (SPECT)/CT was found positive in $4 / 6$ of patients with bilateral and segmental PE in 3/4 of patients. From these data, the authors concluded that Q-SPECT/ CT has clinical utility for diagnosing PE in such COVID19 patients where there is a contraindication for iodinated contrast media [2]. Even if the incidence of PE is known to be increased in COVID-19 patients [3], we agree with Lavinia Monaco et al. that all the heterogeneities of lung perfusion patterns found in SPECT/CT during COVID-19 must not be only attributed to PE [1]. As they pointed out in their letter (and illustrated in their Fig. 1) [1], perfusion SPECT/TC is not only able to confirm PE (segmental perfusion defect of a normally aerated lung area at CT images) but can also reveal increased perfusion in consolidated or hypoventilated lung regions. Such mismatch abnormality

This article is part of the Topical Collection on Letter to the Editor.

\section{Vincent Jounieaux}

jounieaux.vincent@chu-amiens.fr

1 Pneumology Department, University Hospital Centre, Amiens, France

2 Cardiac, Thoracic-Vascular and Respiratory Intensive Care Unit, Department of Anesthesia and Critical Care, University Hospital Centre, Amiens, France

3 Nuclear Medicine Department, University Hospital Centre, Amiens, France

4 Cliniques Universitaires Saint-Luc, Université Catholique de Louvain, Brussels, Belgium between perfusion and ventilation may be attributed to some loss of pulmonary hypoxic vasoconstriction (HPV) and accounts in part in the COVID-19 related hypoxemia. However, using a mathematical model of lung perfusion in normal and injured compartments, Herrmann et al. have concluded that impairment of HPV alone cannot reproduce the same level of severe hypoxia at low values of fraction of injured lung [4] as found by Gattinoni et al. [5]. More, Yao et al. have shown on lung histopathologic pattern of COVID19 patients that the blood vessels of alveolar septum were congested, oedematous, and widened; and that the COVID19 infection, while mainly distributed in the lung, involves the vessels, heart, liver, kidney, and other organs [6]. More recently, Ackermann et al. found ultrastructural damages to the endothelium, the presence of Sars-Cov-2 in endothelial cells, as well as a pulmonary angiogenesis observed since day 4 of hospital admission and which significantly increases with time [7]. In COVID-19 patients, Lang et al. observed three major findings from dual-energy CT on the images of pulmonary blood volume perfusion: preferentially increased perfusion of the lungs proximal to areas of lung opacities, areas of decreased perfusion corresponding to peripheral lung opacities, and a halo of increased perfusion surrounding peripheral areas of consolidation [8]. Such vascular abnormalities could be also found in SPECT/CT through an increased perfusion in normally aerated lung regions (or hyperventilated) [9], as shown, but not described, in Fig. 1a of their letter (areas of augmented perfusion in the right middle lobe despite any evident parenchyma lesions on CT at this level) [1]. We believe that such mismatches may reflect the specific intrapulmonary shunt that we suggest to be the cornerstone of the COVID-19 disease [10] and explain the so-called COVID-19 related "happy hypoxic state." Indeed, we believe that COVID-19 is a vascular disease, inducing an intrapulmonary shunt (as in hepatopulmonary syndrome [11]) through an increase perfusion of normally (or hyperventilated) lung areas (i.e., without any lung parenchyma lesions) [12]. These mismatches result in a mild initial 
hypoxemia leading to a compensatory increase in minute ventilation. Because $\mathrm{CO}_{2}$ is much more diffusible than $\mathrm{O}_{2}$, hyperventilation would rapidly lead to hypocapnia which is known to be a powerful inhibitor of the ventilation. We have previously shown that below a $\mathrm{PaCO}_{2} 29.3 \mathrm{mmHg}$, deep oxygen desaturations (up to $64 \%$ ) are unable to elicit an increase in minute ventilation in normal subjects [13]. This results in the so-called "happy hypoxia" which is a rare situation during hospitalization [14], as alveolar damage is usually present at this time of the COVID-19 infection. Indeed, associated lung parenchyma lesions limit hypocapnia, aggravate hypoxemia, and hide the presence of the vascular component in the form of intrapulmonary shunting. Among the huge heterogeneity of lung perfusion SPECT/ CT patterns observed in COVID-19 patients, one must be vigilant especially to normal lung areas with increased perfusion; around or at distance of areas of COVID-19 related consolidations. In such situations, it seems crucial for us to track the intrapulmonary shunt, either by performing a planar image of the brain immediately after the lung perfusion SPECT/CT acquisition (to detect an abnormal brain uptake) or through a contrast-enhanced echocardiography [12].

\section{Declarations}

Competing interests The authors declare no competing interests.

\section{References}

1. Monaco L, Crivellaro C, Cressoni M, Foti G, Landoni C, Messa C, Guerra L. The heterogeneity of lung perfusion patterns in SPECT/CT during COVID-19: not only embolism. Eur J Nucl Med Mol Imaging. 2021;5:1-2. https://doi.org/10.1007/ s00259-021-05377-1.

2. Das JP, Yeh R, Schöder H. Clinical utility of perfusion (Q)-singlephoton emission computed tomography (SPECT)/CT for diagnosing pulmonary embolus (PE) in COVID-19 patients with a moderate to high pre-test probability of PE. Eur J Nucl Med Mol Imaging. 2021;48(3):794-9.

3. Kaminetzky M, Moore W, Fansiwala K, Babb JS, Kaminetzky D, Horwitz LI, McGuinness G, Knoll A, Ko JP. Pulmonary embolism at CT pulmonary angiography in patients with COVID-19. Radiol Cardiothorac Imaging. 2020;2(4):e200308.

4. Herrmann J, Mori V, Bates JHT, Suki B. Can hyperperfusion of nonaerated lung explain COVID-19 hypoxia? Res Sq. 2020;rs.3.rs-32949. https://doi.org/10.21203/rs.3.rs-32949/v1

5. Gattinoni L, Coppola S, Cressoni M, Busana M, Rossi S, Chiumello D. COVID-19 does not lead to a "typical" acute respiratory distress syndrome. Am J Respir Crit Care Med. 2020;201(10):1299-300.

6. Yao XH, Li TY, He ZC, Ping YF, Liu HW, Yu SC, Mou HM, Wang LH, Zhang HR, Fu WJ, Luo T, Liu F, Guo QN, Chen C, Xiao HL, Guo HT, Lin S, Xiang DF, Shi Y, Pan GQ, Li QR, Huang X, Cui Y, Liu XZ, Tang W, Pan PF, Huang XQ, Ding YQ, Bian XW. A pathological report of three COVID-19 cases by minimal invasive autopsies. Zhonghua Bing Li Xue Za Zhi. 2020;49(5):411-7.

7. Ackermann M, Verleden SE, Kuehnel M, Haverich A, Welte T, Laenger F, Vanstapel A, Werlein C, Stark H, Tzankov A, Li WW, Li VW, Mentzer SJ, Jonigk D. Pulmonary vascular endothelialitis, thrombosis, and angiogenesis in Covid-19. N Engl J Med. 2020;383(2):120-8.

8. Lang M, Som A, Mendoza DP, Flores EJ, Reid N, Carey D, Li MD, Witkin A, Rodriguez-Lopez JM, Shepard JO, Little BP. Hypoxaemia related to COVID-19: vascular and perfusion abnormalities on dual-energy CT. Lancet Infect Dis. 2020;20(12):1365-6.

9. Cobes N, Guernou M, Lussato D, Queneau M, Songy B, Bonardel G, Grellier JF. Ventilation/perfusion SPECT/CT findings in different lung lesions associated with COVID-19: a case series. Eur J Nucl Med Mol Imaging. 2020;47(10):2453-60.

10. Mahjoub Y, Rodenstein DO, Jounieaux V. Severe Covid-19 disease: rather AVDS than ARDS? Crit Care. 2020;24(1):327.

11. Rodríguez-Roisin R, Krowka MJ. Hepatopulmonary syndrome-a liver-induced lung vascular disorder. N Engl J Med. 2008;358(22):2378-87.

12. Jounieaux V, Basille D, Abou-Arab O, Guillaumont MP, Andrejak C, Mahjoub Y, Rodenstein DO. Pure SARS-CoV-2 related AVDS (Acute Vascular Distress Syndrome). BMC Infect Dis. 2021;21(1):122.

13. Jounieaux V, Parreira VF, Aubert G, Dury M, Delguste P, Rodenstein DO. Effects of hypocapnic hyperventilation on the response to hypoxia in normal subjects receiving intermittent positivepressure ventilation. Chest. 2002;121(4):1141-8.

14. Jounieaux V, Rodenstein DO, Mahjoub Y. On happy hypoxia and on sadly ignored "acute vascular distress syndrome" in patients with COVID-19. Am J Respir Crit Care Med. 2020;202(11):15989. https://doi.org/10.1164/rccm.202006-2521LE.

Publisher's note Springer Nature remains neutral with regard to jurisdictional claims in published maps and institutional affiliations. 